\title{
Tumor-associated macrophages favor C26 murine colon carcinoma cell proliferation in an oxidative stress-dependent manner
}

\author{
LAVINIA LUPUT ${ }^{1,2}$, EMILIA LICARETE ${ }^{1,2}$, ALINA SESARMAN $^{1,2}$, LAURA PATRAS $^{1,2}$, \\ MARIUS COSTEL ALUPEI $^{1,2}$ and MANUELA BANCIU ${ }^{1,2}$
}

\begin{abstract}
${ }^{1}$ Department of Molecular Biology and Biotechnology, Faculty of Biology and Geology, Babes-Bolyai University, 400006 Cluj-Napoca; ${ }^{2}$ Molecular Biology Centre, Institute for Interdisciplinary Research in Bio-Nano-Sciences, Babes-Bolyai University, 400271 Cluj-Napoca, Romania
\end{abstract}

Received August 4, 2016; Accepted September 20, 2016

DOI: $10.3892 /$ or.2017.5466

\begin{abstract}
The role of tumor-associated macrophages (TAMs) in the development of colon carcinoma is still controversial. Therefore, the present study aimed to investigate the TAM-driven processes that may affect colon cancer cell proliferation. To achieve this purpose, murine macrophages were co-cultured with $\mathrm{C} 26$ murine colon carcinoma cells at a cell density ratio that approximates physiological conditions for colon carcinoma development in vivo. In this respect, the effects of TAM-mediated angiogenesis, inflammation and oxidative stress on the proliferative capacity of C26 murine colon carcinoma cells were studied. To gain insight into the TAM-driven oxidative stress, NADPH oxidase, the main pro-oxidant enzyme in macrophages, was inhibited. Our data revealed that the stimulatory effects of TAMs on C26 cell proliferation may be related mainly to their pro-oxidant actions exerted by NADPH oxidase activity, which maintains the redox status and the angiogenic capacity of the tumor microenvironment. Additionally, the anti-inflammatory and pro-angiogenic effects of TAMs on tumor cells were found to create a favorable microenvironment for $\mathrm{C} 26$ colon carcinoma development and progression. In conclusion, our data confirmed the protumor role of TAMs in the development of colon carcinoma in an oxidative stress-dependent manner that potentiates the angiogenic capacity of the tumor microenvironment. These data may offer valuable information for future tumor-targeted therapies based on TAM 're-education' strategies.
\end{abstract}

Correspondence to: Dr Manuela Banciu, Department of Molecular Biology and Biotechnology, Faculty of Biology and Geology, Babes-Bolyai University, 5-7 Clinicilor Street, 400006 Cluj-Napoca, Romania

E-mail: manuela.banciu@ubbcluj.ro

Key words: tumor-associated macrophages, colon carcinoma, proliferation, oxidative stress, NADPH oxidase, angiogenesis, inflammation

\section{Introduction}

Among all cell types in the tumor microenvironment, immune system cells are involved in the strongest interaction with tumor cells as a result of the primary necessity of cancer cells to maintain immune cells in a suppressed state to ensure tumor growth and development (1-3). Thus, tumor cells release paracrine signals such as pro-tumor cytokines (IL-4 and TGF- $\beta$ ) that induce the 'education' of cells in the tumor microenvironment converting these initial 'antitumor fighters' into 'protumor slaves'. Among the immune cell populations present in tumor tissue, 'the educated' macrophages, so-called tumor-associated macrophages (TAMs) seem most important in supporting tumor growth via coordination of angiogenesis, inflammation, oxidative stress, invasion, and the metastatic capacity of tumors (3-5). The protumor education of macrophages is facilitated by high phenotypic plasticity of this cell type that has multiple intermediary phenotypes ranging from the antitumor M1 or 'classically activated' macrophage type (characterized mainly by high levels of IL-12 and low levels of IL-10) to the protumor, M2 type (characterized mainly by high levels of IL-10 and low levels of IL-12) specific for TAMs $(6,7)$. Thus, TAMs are known to be an important source of pro-inflammatory molecules (TNF $\alpha$, IL-1, 6, 8, 10, 12p40, MCP-1 and $\mathrm{PGE}_{2}$ ), pro-angiogenic proteins (VEGF, bFGF, IGF, TNF- $\alpha$ and MMPs) as well as immunosuppressive cytokines (IL-10 and TGF- $\beta$ ) $(2,3,5,8)$. Moreover, TAM-induced chronic inflammation produces reactive oxygen species (ROS) with a key role in the activation of redox sensitive transcription factors (NF- $\kappa \mathrm{B}, \mathrm{AP}-1$ and Egr-1) that orchestrate all processes involved in tumor progression such as immunosuppression, cell proliferation, angiogenesis, and metastasis (9-15).

Nevertheless, the role of TAMs in the development of colon carcinoma is still controversial as the presence of infiltrated macrophages in the tumor microenvironment is associated with good (16-18), as well as poor prognosis (19).

Therefore, the present study aimed to investigate the main TAM-driven processes that can affect colon carcinoma development. In this respect, we aimed to ascertain how TAM-mediated angiogenesis, inflammation, and oxidative 
stress can affect the proliferative capacity of C26 murine colon carcinoma cells, when they are co-cultivated with TAMs in vitro. To gain insight into the mechanisms by which TAMs influence the proliferation of C26 cells, key molecules involved in the coordination of the protumor processes presented above were screened. Our results demonstrated that TAM-regulated oxidative stress is the main process that affects $\mathrm{C} 26$ colon carcinoma cell proliferation via the activity of macrophage NADPH oxidase that maintains the physiological range of the proliferative levels of reactive oxygen species (ROS) and enhances the production of angiogenic proteins in the tumor microenvironment.

\section{Materials and methods}

Cell line and culture conditions. C26 murine colon carcinoma cells (Cell Lines Service GmbH, Eppelheim, Germany) were cultured in RPMI-1640 medium (Lonza, Group AG, Basel, Switzerland), supplemented with $10 \%$ heat-inactivated fetal bovine serum (FBS) (HyClone, GE Healthcare Life Sciences, Logan, UT, USA), as a monolayer at $37^{\circ} \mathrm{C}$ in a humidified atmosphere containing $5 \% \mathrm{CO}_{2}$.

Co-culture of C26 tumor cells and macrophages. Macrophages were freshly harvested from the peritoneal cavity of 6- to 8-week BALB/c mice (Cantacuzino Institute, Bucharest, Romania) that had been intraperitoneally injected with $1 \mathrm{ml}$ of 3\% thioglycollate (Sigma-Aldrich Chemie GmbH, Munich, Germany). After 3 days, elicited macrophages were isolated by intraperitoneal lavage as previously reported (20). Co-cultures were prepared by seeding C26 tumor cell suspensions on macrophage monolayers; the density ratio between macrophages and tumor cells in co-cultures being 1:4. Previous studies have proved that this cell density ratio ensures the optimal cytokine interplay between tumor cells and macrophages that provides an approximation of physiological conditions for colon carcinoma development in vivo (21). Experiments were performed according to national regulations and were approved by the University Animal Experiments Ethics Committee (registration no. 31375/06.04.2015).

Cell proliferation assay. The proliferative capacity of the C26 colon carcinoma cells was evaluated for the standard culture of $\mathrm{C} 26$ cells as well as for the co-culture of C26 cells with murine peritoneal macrophages. Thus, C26 cells $\left(1 \times 10^{3} /\right.$ well) cultured alone or along with peritoneal macrophages at a density ratio of 1:4, were seeded into 96-well plates and incubated for $48 \mathrm{~h}$. The proliferation rate was expressed as number of absorbance units/hours of incubation (22) and tested using ELISA BrdU-colorimetric immunoassay (Roche Applied Science, Penzberg, Germany) according to the manufacturer's instructions as previously described (23). This method is based on the incorporation of bromodeoxyuridine (BrdU), a pyridine analogue, instead of thymidine into the DNA of the proliferating cells. C26 colon carcinoma cells were incubated with BrdU solution for $24 \mathrm{~h}$ and the culture medium was completely removed from each well. Following this step, the cells were fixed and the DNA was denatured. The incorporated BrdU in the newly synthesized cellular DNA was detected by adding a monoclonal antibody anti-BrdU-POD to each well, conjugated with peroxidase. The antibody was removed after $1 \mathrm{~h}$ of incubation, and the cells were washed 3 times with phosphate-buffered saline. A peroxidase substrate (tetramethyl-benzidine) was added to each well, and the immune complexes were detected by measuring the absorbance of the reaction product at $450 \mathrm{~nm}$ with a reference wavelength of $655 \mathrm{~nm}$.

Preparation of cell culture lysates. Cells cultures were lysed with lysis buffer containing $10 \mathrm{mM}$ HEPES (pH 7.0), $200 \mathrm{mM}$ $\mathrm{NaCl}, 1 \%$ Triton $\mathrm{X}-100,10 \mathrm{mM} \mathrm{MgCl}_{2}, 1 \mathrm{mM}$ dithiothreitol and protease inhibitor cocktail tablets (cOmplete; Roche Diagnostics $\mathrm{GmbH}$, Mannheim, Germany). The homogenate was incubated for $30 \mathrm{~min}$ on ice, and then centrifuged for $10 \mathrm{~min}$ at $12,000 \mathrm{x} \mathrm{g}$, at $4^{\circ} \mathrm{C}$, and the supernatant was collected and stored at $-80^{\circ}$ for further molecular measurements. For nuclear extraction, cell cultures were lysed with extraction buffer containing $20 \mathrm{mM}$ HEPES (pH 7.6), 20\% glycerol (v/v), $10 \mathrm{mM} \mathrm{NaCl}, 1.5 \mathrm{mM}$ $\mathrm{MgCl}_{2}, 0.2 \mathrm{mM}$ EDTA, $0.1 \%$ Triton X-100 (v/v), $1 \mathrm{mM}$ DTT, $1 \mathrm{mM}$ phenylmethylsulfonyl fluoride (PMSF), $10 \mu \mathrm{g} / \mathrm{ml}$ leupeptin, $10 \mu \mathrm{g} / \mathrm{ml}$ pepstatin, $100 \mu \mathrm{g} / \mathrm{ml}$ aprotinin, and phosphatase inhibitor PhosSTOP tablets (Roche Diagnostics GmbH). Then, cell lysates were centrifuged for $5 \mathrm{~min}$ at 2,500 $\mathrm{x} \mathrm{g}$, at $4^{\circ} \mathrm{C}$, and the pellet was resuspended in extraction buffer supplemented with $\mathrm{NaCl}$ up to $500 \mathrm{mM}$ (24). After $1 \mathrm{~h}$ of incubation on the rocking platform, at $4^{\circ} \mathrm{C}$, the nuclei were lysed and separated by centrifugation $\left(10 \mathrm{~min}\right.$ at $18,000 \mathrm{xg}$, at $\left.4^{\circ} \mathrm{C}\right)$. The supernatants were retained (nuclear fractions) and the protein concentration was determined by the Bradford assay (Sigma-Aldrich Chemie $\mathrm{GmbH}$ ) (25).

Western blot analysis of $N F-\kappa B$ levels. To determine the link between the levels of the inflammatory transcription factor $\mathrm{NF}-\kappa \mathrm{B}$ (nuclear factor- $\kappa \mathrm{B}$ ) (26) and C26 cell proliferation, we performed western blot analysis for the expression of the active form of $N F-\kappa B$ [when the p65 subunit of $N F-\kappa B$ is phosphorylated (pNF- $\kappa \mathrm{B}-\mathrm{p} 65)]$ as well as expression of the total NF- $\mathrm{B}-\mathrm{p} 65$ subunit (pNF- $\kappa \mathrm{B}-\mathrm{p} 65$ and inactive form of $N F-\kappa B$ when p65 subunit is unphosphorylated form of NF- $\kappa$ B). To this aim, the levels of pNF- $\kappa \mathrm{B}-\mathrm{p} 65$ in nuclear extracts were determined and expressed as the percentage of the total amount of $\mathrm{NF}-\kappa \mathrm{B}$ in the whole cell lysates. Thus, $25 \mu \mathrm{g} /$ well of total protein from each lysate were loaded onto a $10 \%$ polyacrylamide gel. Electrophoresis was performed at $95 \mathrm{mV}$ and then the protein fractions were electro-transferred onto a nitrocellulose membrane at $100 \mathrm{mV}$ for $40 \mathrm{~min}$. The membranes were blocked overnight at $4{ }^{\circ} \mathrm{C}$ with $5 \%$ skimmed milk powder (Bio-Rad Laboratories, Hercules, CA, USA) in Tris-buffered saline containing 0.1\% Tween-20 (TBS-T), under constant shaking. After that, the membranes were incubated for $2 \mathrm{~h}$ at room temperature with either monoclonal mouse IgG anti-mouse NF- $\mathrm{NB}$ p65 primary antibody or polyclonal rabbit IgG anti-mouse $\mathrm{pNF}-\kappa \mathrm{B}$ p 65 primary antibody (both from Santa Cruz Biotechnology, Dallas, TX, USA) diluted 1:500 in TBS-T, with 5\% skimmed milk powder. As the loading control, $\beta$-actin expression was determined using a polyclonal rabbit IgG anti-mouse $\beta$-actin primary antibody (Santa Cruz Biotechnology) diluted 1:500 with 5\% skim milk powder in TBS-T. Membranes were washed with TBS-T and incubated at room temperature for $1 \mathrm{~h}$ with goat IgG anti- 
mouse IgG secondary antibody HRP-conjugated (Santa Cruz Biotechnology) diluted 1:3,000 in TBS-T, for NF- $\kappa$ B p65 detection. To determine $\beta$-actin and pNF- $\kappa \mathrm{B}-\mathrm{p} 65$ levels, a goat IgG anti-rabbit IgG secondary antibody HRP-conjugated (Santa Cruz Biotechnology) diluted 1:4,000 in TBS-T was used. Proteins were detected using Clarity ${ }^{\mathrm{TM}}$ Western ECL (Bio-Rad Laboratories) and the membranes were exposed to an X-ray film (Kodak, Knoxville, TN, USA) for $2 \mathrm{~min}$. The films were developed and analyzed using TotalLab Quant Software version 12 for Windows. Each sample was determined in duplicate.

Angiogenic protein array analysis. The expression levels of inflammatory/angiogenic proteins in cells cultivated under both culture conditions were investigated by performing a screening for 24 proteins involved in angiogenesis using RayBio ${ }^{\circledR}$ Mouse Angiogenic Cytokine Antibody Array kit (RayBiotech, Inc., Norcross, GA, USA) as previously described (23). One array membrane containing 24 types of primary antibodies against specific proteins was incubated with $200 \mu \mathrm{g}$ of proteins of cell lysates, for $2 \mathrm{~h}$ at room temperature. Then, a mixture of secondary biotin-conjugated antibodies against the same angiogenic factors as those for primary antibodies, was added to the membranes and incubated overnight at $4^{\circ} \mathrm{C}$, followed by incubation with HRP-conjugated streptavidin for $2 \mathrm{~h}$. Each incubation step was followed by 5 washing steps. Thereafter, the membranes were incubated with a mixture of 2 detection buffers for $1 \mathrm{~min}$, exposed to an X-ray film (Kodak) for $2 \mathrm{~min}$, and then the films were developed. The protein expression levels were quantified by measuring the intensity of the color of each spot on the membranes, in comparison to the positive control spots already bound to the membranes, using TotalLab Quant Software version 12 for Windows. The expression of each angiogenic/inflammatory protein in cell lysates was determined in duplicate.

HPLC assessment of malondialdehyde levels. To investigate whether TAM-generated oxidative stress affects $\mathrm{C} 26$ cell proliferation, we quantified the amount of malondialdehyde (MDA) through high-performance liquid chromatography (HPLC) in lysates obtained from C26 cells as well as C26 cells and macrophages (27). Before HPLC quantification of MDA, sample deproteinization was performed using $\mathrm{HClO}_{4}(27)$. Then, the samples were centrifuged at 4,500 $\mathrm{x}$ g for $5 \mathrm{~min}$ and $100 \mu \mathrm{l}$ of each supernatant was analyzed by HPLC. The column type was RP18 (5 $\mu \mathrm{m})$ (Supelco, Bellefonte, PA, USA) and the mobile phase consisted of $30 \mathrm{mM} \mathrm{KH}_{2} \mathrm{PO}_{4} /$ methanol in a volume ratio of $65: 35$. Flow rate was set at $0.5 \mathrm{ml} / \mathrm{min}$ and MDA was measured using a UV detector set at $254 \mathrm{~nm}$. The retention time of MDA was $\sim 5.4 \mathrm{~min}$. Data were normalized to the protein concentration from the cell lysates and expressed as $\mu \mathrm{g} \mathrm{MDA} / \mathrm{mg}$ protein. Each sample was determined in duplicate.

Assessment of total antioxidant nonenzymatic capacity. This assay was based on the method described by Erel (28) and was used to determine the ability of nonenzymatic antioxidants (e.g. uric acid, vitamins, sulfhydryl groups of proteins and glutathione) to decolorize the blue-green oxidized 2,2'-azinobis(3-ethylbenzothiazoline-6-sulfonate (ABTS+) proportionally to cell nonenzymatic antioxidant concentrations and it can be monitored by measuring the absorbance $660 \mathrm{~nm}$. The results are expressed as $\mu$ moles of nonenzymatic antioxidants/mg of protein. The samples were measured in duplicate.

Measurement of catalase activity. The catalytic activity of catalase was assessed via the method described by Aebi (29). Catalase activity was monitored by measuring the decrease of hydrogen peroxide absorbance at $240 \mathrm{~nm}$ during $1 \mathrm{~min}$. One catalytic unit of catalase was defined as the amount of enzyme that decomposed $1 \mu \mathrm{mol}$ hydrogen peroxide $/ \mathrm{min}$ at $25^{\circ} \mathrm{C}$ and $\mathrm{pH}$, 7.0. Catalase activity is expressed as units of catalytic activity/mg of protein.

Inhibition of NADPH oxidase function. To assess indirectly the role of macrophage NADPH oxidase in the generation of physiological levels of ROS in co-culture microenvironment, cells were treated with $300 \mu \mathrm{M}$ of apocynin, a NADPH oxidase inhibitor that acts by blocking the assembly of NADPH oxidase subunits (Santa Cruz Biotechnology) for $48 \mathrm{~h}$. Moreover, to determine whether NADPH oxidase-generated oxidative stress can modulate $\mathrm{C} 26$ cell proliferation, tumor angiogenesis and inflammation, all assays described above were performed after co-culture incubation with apocynin.

Statistical analysis. Data from different experiments are expressed as mean \pm standard deviation (SD). The differences between different protumor processes under standard and co-culture conditions were evaluated using unpaired t-test. The differences between the production of angiogenic proteins in cells from standard culture and co-culture were analyzed by two-way ANOVA with Bonferroni correction for multiple comparisons. Correlations between different parameters were evaluated using Pearson correlation coefficient, r. All statistical analyses were performed using GraphPad Prism version 6 for Windows, GraphPad Software (San Diego, CA, USA). A P-value $<0.05$ was considered significant.

\section{Results}

TAMs stimulate the proliferation of C26 colon carcinoma cells. The effect of TAMs on C26 cell proliferation after $48 \mathrm{~h}$ of incubation was evaluated by comparing the proliferation rate of C26 murine carcinoma cells cultivated alone with the proliferation rate of $\mathrm{C} 26$ cells co-cultivated with macrophages (Fig. 1) at a cell density ratio of 4:1 (C26 cells:macrophages) that ensures an approximation of physiological conditions for colon carcinoma development in vivo (21). Our data showed that C26 cells proliferated more rapidly in the presence of macrophages (by 28\%; $\mathrm{P}<0.01$ ) than those cultivated alone. Therefore, the involvement of TAMs in the coordination of main processes responsible for $\mathrm{C} 26$ cell proliferation was further investigated.

Anti-inflammatory effects of TAMs on C26 colon carcinoma cells. To investigate whether TAMs stimulate the proliferation of $\mathrm{C} 26$ cells through the modulation of the production of the key inflammatory transcription factor, NF- $\mathrm{kB}$, we analyzed by western blotting the levels of the active form of this protein (NF- $\kappa \mathrm{B}$ with p65 subunit phosphorylated, pNF- $\kappa \mathrm{B}-\mathrm{p} 65$ ) as well as the production of total NF- $\mathrm{KB}$ in $\mathrm{C} 26$ cells cultured alone as well as in C26 cells co-cultured with macrophages. 


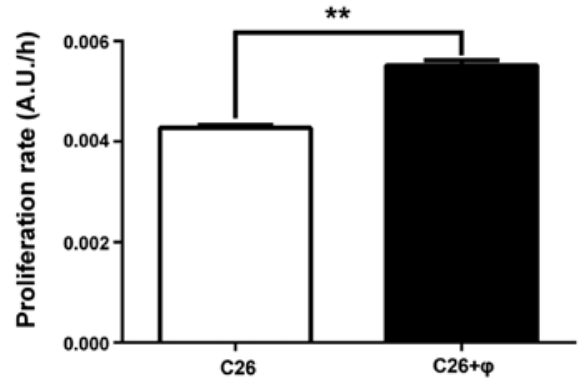

Figure 1. Effects of TAMs on $\mathrm{C} 26$ cell proliferation. The proliferation rate of C26 cells in standard culture as well as in the presence of TAMs was assessed after $48 \mathrm{~h}$ of incubation in culture media. Data are shown as the mean proliferation rate, expressed in absorbance units (A.U.)/h of incubation \pm SD; $n=5$ measurements. C26, C26 murine colon carcinoma cells; $\mathrm{C} 26+\phi, \mathrm{C} 26$ colon carcinoma cells co-cultured with intraperitoneal murine macrophages $(\phi)$ at a cell density ratio of 4:1 (C26 cells:macrophages). To compare the rate of $\mathrm{C} 26$ cell proliferation in standard culture with $\mathrm{C} 26$ cell proliferation in coculture with macrophages, an unpaired t-test was used; ${ }^{* *} \mathrm{P}<0.01$

The results are presented as percentages of pNF- $\kappa \mathrm{B}-\mathrm{p} 65$ production from the amount of total NF- $\mathrm{KB}-\mathrm{p} 65$ in the cell lysates (Fig. 2). Although, the levels of total NF- $\mathrm{BB}$ were similar in lysates obtained from standard culture of $\mathrm{C} 26$ cells with those from co-culture, the co-cultivation of $\mathrm{C} 26$ cells with TAMs reduced drastically the levels of the active form of $\mathrm{NF}-\kappa \mathrm{B}$ by $70 \%(\mathrm{P}<0.001)$ compared to its production in $\mathrm{C} 26$ cells cultivated under standard conditions. These results are in accordance with the previously described anti-inflammatory role of TAMs in the tumor microenvironment due to the suppression of NF-kB activation $(8,30)$.

Angiogenic effects of TAMs on C26 colon carcinoma cells. To assess the link between proliferative effects of TAMs on C26 cells and TAM-driven angiogenesis, 24 proteins involved in this process were screened by protein array (RayBio Mouse Angiogenic Cytokine Antibody Array kit; RayBiotech, Inc.) in C26 cell lysates, and also in lysates obtained after C26 cell cultivation with TAMs for $48 \mathrm{~h}$. The results presented in Table I show an overall enhancement of the production of the angiogenic proteins with $112 \%$ in the cell lysates obtained under co-culture conditions compared to their production in $\mathrm{C} 26$ cells cultivated alone. More specifically, after $48 \mathrm{~h}$ of incubation of $\mathrm{C} 26$ cells with macrophages, the levels of insulin-like growth factor-II (IGF-II), interleukin-9 (IL-9), interleukin-12 subunit p40 (IL-12p40), Fas ligand (FasL), vascular endothelial growth factor (VEGF) and thrombopoietin (TPO), were stimulated very strongly (by 200-260\%), and the levels of macrophage-colony stimulating factor (M-CSF), interleukin-1 $\alpha$ (IL-1 $\alpha$ ), interleukin-1 $\beta$ (IL-1 $\beta$ ), tumor necrosis factor- $\alpha$ (TNF- $\alpha$ ), monocyte chemoattractant protein-1 (MCP-1), leptin and platelet factor-4 (PF-4), were strongly enhanced (by 100-200\%), while interleukin-6 (IL-6), eotaxin, basic fibroblast growth factor (bFGF), tissue inhibitor of metalloproteinase-2 (TIMP-2) and interferon- $\gamma$ (IFN- $\gamma$ ) were moderately stimulated (by 30-100\%) in comparison with the production of the same proteins in standard C26 cell culture. Only the expression of granulocyte-colony stimulating factor (G-CSF) and interleukin-13 (IL-13), was inhibited slightly and statistically significantly (by $25-35 \%$ ) in the co-culture model compared to their levels in the $\mathrm{C} 26$ cell lysates.
A

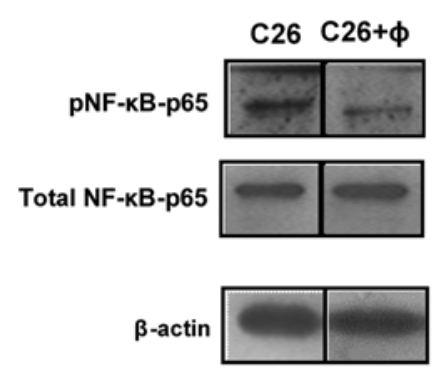

B

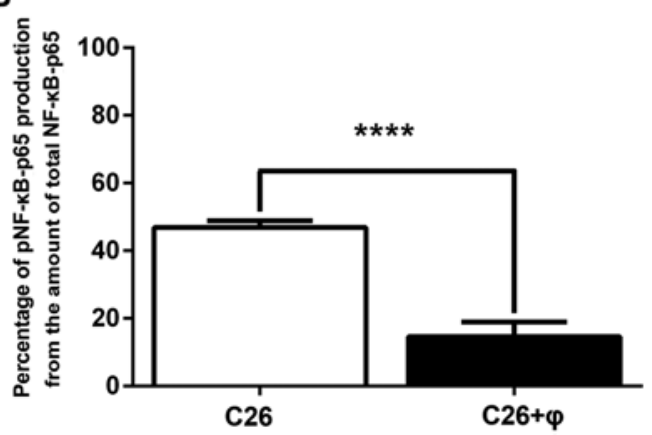

Figure 2. Effects of TAMs on the expression of NF-кB. (A) The levels of the active form of NF- $\kappa \mathrm{B}$ (when the p65 subunit of $\mathrm{NF}-\kappa \mathrm{B}$ is phosphory-

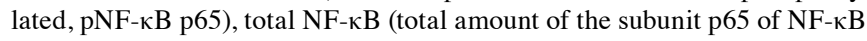
in active as well as in inactive form, total $\mathrm{NF}-\kappa \mathrm{B}$ p65) and $\beta$-actin in $\mathrm{C} 26$ cells cultivated alone (C26), and in C26 cells co-cultured with macrophages $(\mathrm{C} 26+\phi)$ after $48 \mathrm{~h}$ of incubation with culture media as assessed by western blot analysis. $\beta$-actin was used as loading control. (B) Percentages of the amount of the active form of NF- $\kappa \mathrm{B}$ over the total NF- $\kappa \mathrm{B}$ amount. To compare $\mathrm{NF}-\kappa \mathrm{B}$ levels in $\mathrm{C} 26$ cell standard culture and cell co-culture, an unpaired t-test was used; ${ }^{* * * *} \mathrm{P}<0.0001$. The results represent the mean $\pm \mathrm{SD}$ of 4 independent measurements.

Pro-oxidant effects of TAMs on C26 colon carcinoma cells. To determine whether the proliferative activity of TAMs on C26 colon carcinoma cells is related to their modulatory effects on oxidative stress, the levels of a general oxidative stress markerMDA as well as catalytic activity of catalase and production of nonenzymatic antioxidant systems were assessed and are shown in Fig. 3A-C. Moreover, the involvement of the main pro-oxidant enzyme in macrophages, NADPH oxidase (31) in the maintenance of the proliferative levels of oxidative stress in the tumor microenvironment were addressed (Fig. 4A-D). Our results confirmed that TAMs are important in the generation of tumor oxidative stress since MDA levels were significantly enhanced (2-fold higher; $\mathrm{P}<0.05)$ in the lysates from co-culture of $\mathrm{C} 26$ cells and macrophages compared to their levels in C26 cell lysates (Fig. 3A). These data were also supported by the results regarding the higher amount of nonenzymatic antioxidant systems in co-culture lysates compared to C26 cell lysates (2-fold higher production in co-culture lysates compared to their production in $\mathrm{C} 26$ cell lysates, $\mathrm{P}=0.04$ ) (Fig. 3C). As catalase activity was only slightly increased and not statistically significant in the presence of macrophages (Fig. 3B; $\mathrm{P}=0.61$ ), it seems that the main protective mechanism against high levels of ROS in the co-culture model is mediated rather by nonenzymatic antioxidant systems than by catalase. To evaluate further the involvement of the TAM-expressed NADPH-oxidase in maintaining the $\mathrm{C} 26$ carcinoma oxidative stress, TAMs co-cultivated with C26 cells were incubated for $48 \mathrm{~h}$ with an inhibitor of this enzyme (300 $\mu \mathrm{M}$ apocynin) and 
Table I. Effects of TAMs on the production of angiogenic proteins in the co-culture model.

\begin{tabular}{|c|c|}
\hline Angiogenic proteins & $\begin{array}{l}\text { Percentage of inhibition (-) } \\
\text { and stimulation }(+) \text { of } \\
\text { angiogenic proteins in co-culture } \\
\text { of C26 cells and macrophages } \\
\text { compared to standard } \\
\text { culture of C26 cells }\end{array}$ \\
\hline Granulocyte CSF & $-34.65 \pm 3.70^{\mathrm{b}}$ \\
\hline Granulocyte-macrophage CSF & $-26.65 \pm 1.34^{\mathrm{ns}}$ \\
\hline Macrophage-CSF & $191.45 \pm 4.47^{\mathrm{d}}$ \\
\hline Insulin-like growth factor II & $204.54 \pm 0.15^{\mathrm{d}}$ \\
\hline IL-1 $\alpha$ & $190.56 \pm 7.36^{\mathrm{d}}$ \\
\hline IL-1 $\beta$ & $178.60 \pm 0.23^{\mathrm{d}}$ \\
\hline IL-6 & $45.30 \pm 4.99^{c}$ \\
\hline IL-9 & $202.54 \pm 4.50^{\mathrm{d}}$ \\
\hline IL-12p40 & $257.75 \pm 0.30^{\mathrm{d}}$ \\
\hline IL-13 & $-27.91 \pm 1.51^{\mathrm{a}}$ \\
\hline Tumor necrosis factor- $\alpha$ & $169.63 \pm 17.53^{\mathrm{d}}$ \\
\hline Monocyte chemoattractant protein-1 & $186.40 \pm 3.06^{\mathrm{d}}$ \\
\hline Eotaxin & $91.58 \pm 3.85^{\mathrm{d}}$ \\
\hline Fas ligand & $221.19 \pm 11.76^{\mathrm{d}}$ \\
\hline Basic fibroblast growth factor & $31.53 \pm 4.89^{\mathrm{a}}$ \\
\hline Vascular endothelial growth factor & $208.69 \pm 17.80^{\mathrm{d}}$ \\
\hline Leptin & $156.92 \pm 21.90^{\mathrm{d}}$ \\
\hline Thrombopoietin & $207.97 \pm 1.53^{\mathrm{d}}$ \\
\hline TIMP-1 & $-22.52 \pm 3.62^{\mathrm{ns}}$ \\
\hline TIMP-2 & $39.54 \pm 5.53^{\mathrm{b}}$ \\
\hline Platelet factor 4 & $122.50 \pm 0.62^{\mathrm{d}}$ \\
\hline IL-12p70 & $15.10 \pm 13.81^{\mathrm{ns}}$ \\
\hline Interferon- $\gamma$ & $51.94 \pm 3.38^{\mathrm{d}}$ \\
\hline Monokine induced by interferon- $\gamma$ & $17.38 \pm 9.19^{\mathrm{ns}}$ \\
\hline
\end{tabular}

Statistical differences were evaluated using two-way ANOVA with Bonferroni post tests and indicated as follows: ns, not significant, $\mathrm{P}>0.05$; ${ }^{a} \mathrm{P}<0.05 ;{ }^{b} \mathrm{P}<0.01 ;{ }^{\mathrm{C}} \mathrm{P}<0.001$ and ${ }^{\mathrm{d}} \mathrm{P}<0.0001$. TAMs, tumor-associated macrophages; CSF, colony-stimulating factor; IL, interleukin; TIMP, tissue inhibitor of metalloproteinases.

the oxidative stress parameters presented above were evaluated (Fig. 4A-C). As a negative control, a standard culture of C26 cells treated with apocynin was used. No effects on the levels of MDA and nonenzymatic antioxidants and catalase activity were noted after incubation of $\mathrm{C} 26$ cells with apocynin (data not shown). Our data clearly confirmed the principal role of NADPH oxidase in supporting the C26 carcinoma oxidative stress as the MDA levels in cell lysates obtained from co-culture treated with apocynin were reduced to its levels in $\mathrm{C} 26$ cells cultivated alone (Fig. 4A compared to Fig. 3A; $\mathrm{P}=0.08$ ). Neutralization of oxidative stress in the co-culture microenvironment via NADPH oxidase suppression was also accompanied by the reduction in the production of nonenzymatic antioxidant systems (5-fold lower amount after co-culture treatment with apocynin than their amount in cell co-culture with active NADPH oxidase, $\mathrm{P}=0.0027$ ) (Fig. 4C).
A

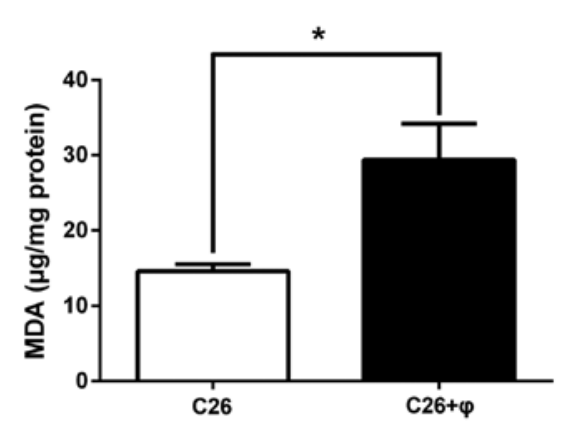

B

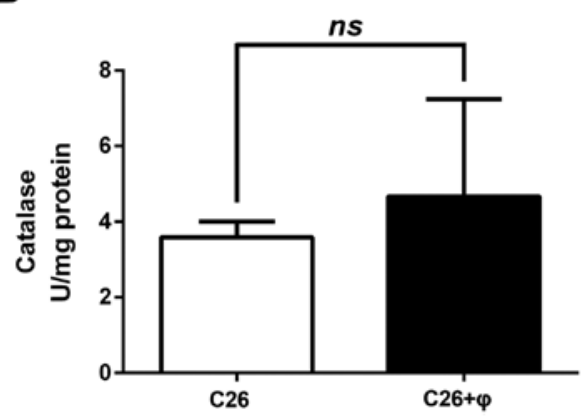

C

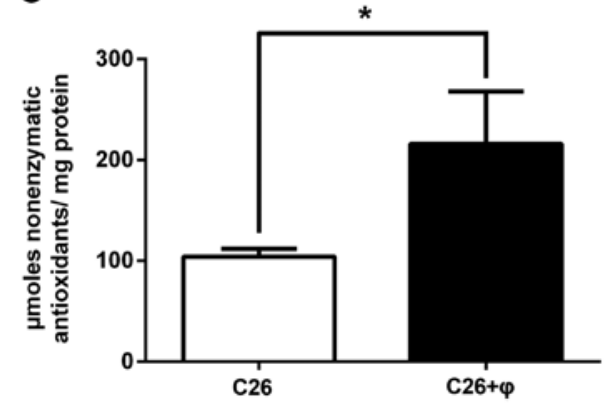

Figure 3. Effects of TAMs on the oxidative stress generated in the co-culture milieu. (A) Malondialdehyde (MDA) concentration, (B) catalytic activity of catalase, and (C) total nonenzymatic antioxidant system levels in the cell lysates obtained from standard culture of C26 murine colon carcinoma cells (C26) and from co-culture of $\mathrm{C} 26$ cells with intraperitoneal macrophages $(\mathrm{C} 26+\phi)$ after $48 \mathrm{~h}$ of incubation. To compare the levels of MDA and nonenzymatic antioxidant defense systems and catalase activity in C26 cell standard culture and in cell co-culture, an unpaired t-test was used; ns, $\mathrm{P}>0.05 ;{ }^{*} \mathrm{P}<0.05$. The results represent the mean $\pm \mathrm{SD}$ of 2 independent measurements.

Moreover, to link the role of NADPH oxidase to stimulatory effects of TAMs on C26 cells, the proliferation of these cancer cells under co-culture conditions in the presence of apocynin was tested. Our data demonstrated that the stimulatory effects of TAMs on C26 cell proliferation were abrogated after NADPH oxidase inhibition in macrophages. Thus, after cell co-culture treatment with apocynin, the $\mathrm{C} 26$ cell proliferation was similar to that of the C26 cells cultivated alone (Fig. 4D compared to Fig. 1; $\mathrm{P}=0.06$ ).

Role of NADPH oxidase in the modulation of the protumor actions of TAMs on C26 cells. To evaluate whether the pro-oxidant effects of TAMs generated via activity of NADPH oxidase can be linked to potential stimulatory actions of TAMs on C26 cell proliferation, C26 murine carcinoma cells were cultured with macrophages in the presence of apocynin 
A

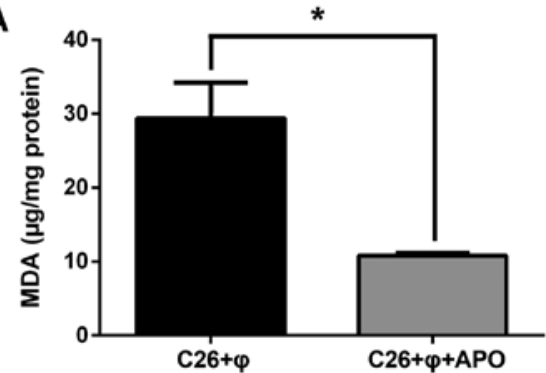

C

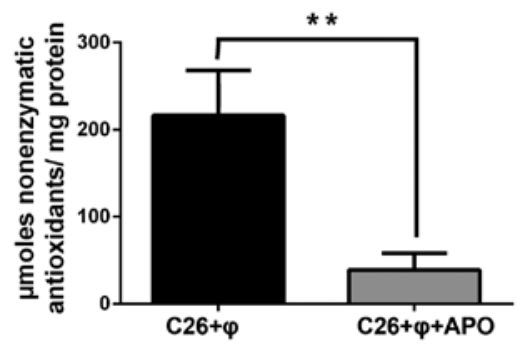

B

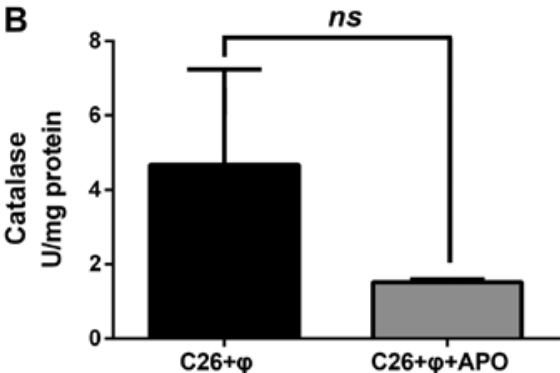

D

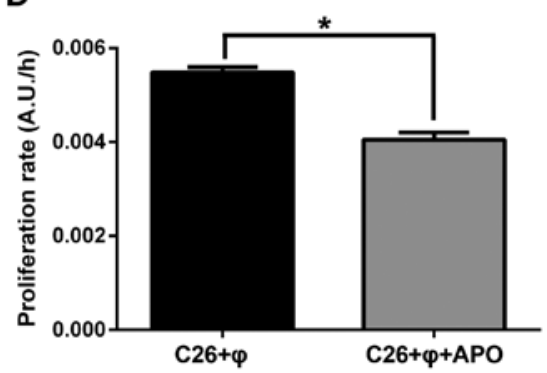

Figure 4. Involvement of TAM NADPH oxidase in the oxidative stress generated in the co-culture of C26 murine colon carcinoma cells and macrophages. C26 cells co-cultured with macrophages in the absence of apocynin $(\mathrm{C} 26+\phi)$ and $\mathrm{C} 26$ cells co-cultured with macrophages in the presence of apocynin (C26+\$+APO) for $48 \mathrm{~h}$ were compared with regard to the levels of (A) MDA, (B) catalytic activity of catalase, (C) total nonenzymatic antioxidant system amount and (D) proliferation rate of the $\mathrm{C} 26$ cells. Data are shown as mean $\pm \mathrm{SD} ; \mathrm{n}=3$ measurements for MDA levels, catalase activity, and total nonenzymatic antioxidant systems assessment and $\mathrm{n}=6$ replicates for proliferation rate. Unpaired t-test was used for statistical comparison; $\mathrm{ns}, \mathrm{P}>0.05 ;{ }^{*} \mathrm{P}<0.05 ;{ }^{* *} \mathrm{P}<0.01$.

A

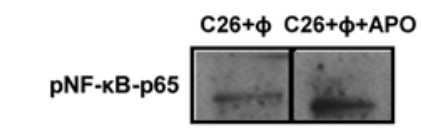

Total NF-kB-p65
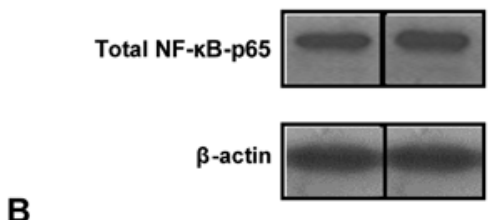

B

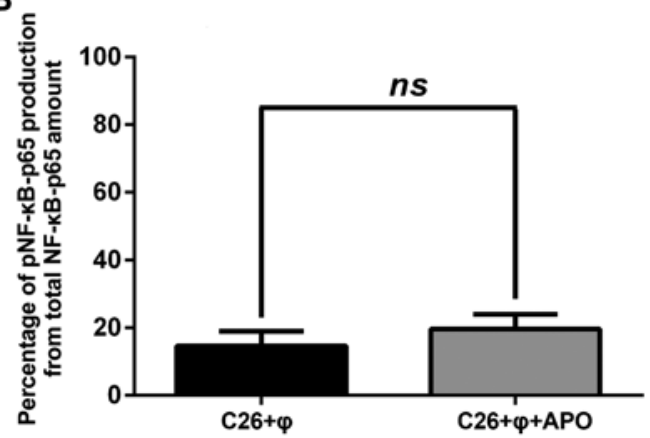

Figure 5. Involvement of TAM NADPH-oxidase in the cell expression of $\mathrm{NF}-\mathrm{kB}$. (A) The levels of the active form of NF- $\mathrm{kB}$ (when the p65 subunit of NF- $\kappa \mathrm{B}$ is phosphorylated, $\mathrm{pNF}-\kappa \mathrm{B}$ p65), total NF- $\mathrm{kB}$ (total amount of subunit 65 of NF- $\mathrm{BB}$, in active as well as in inactive form, total NF- $\mathrm{BB}$ p65), and $\beta$-actin in $\mathrm{C} 26$ cells co-cultured with macrophages in the absence of apocynin $(\mathrm{C} 26+\phi)$ and in $\mathrm{C} 26$ cells co-cultured with macrophages in the presence of apocynin (C26+ $\phi+\mathrm{APO})$ for $48 \mathrm{~h}$ as assessed by western blot analysis. $\beta$-actin was used as a loading control. (B) Percentages of the amount

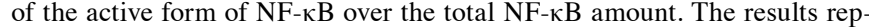
resent the mean $\pm \mathrm{SD}$ of 4 independent measurements. To compare NF-kB levels unpaired t-test was used; $\mathrm{ns}, \mathrm{P}>0.05$.

for $48 \mathrm{~h}$ and then the production of NF- $\mathrm{kB}$ (Fig. 5A and B) as well as of different angiogenic proteins (Table II) were assessed. Our results showed that inhibition of NADPH oxidase in macrophages did not affect the levels of the active form of NF- $\mathrm{BB}$ as well as of total NF- $\mathrm{KB}$ in cell co-culture lysates $(\mathrm{P}=0.35)$ (Fig. 5A and $\mathrm{B}$ ). When $\mathrm{C} 26$ cells co-cultured with macrophages were treated with apocynin, the levels of all angiogenic proteins tested were statistically significantly reduced $(\mathrm{P}<0.0001)$ compared to their production in untreated cell co-culture lysates. On average, NADPH oxidase inhibition reduced the production of these proteins by $63 \%$ in the apocynin-incubated cells compared to their production in the untreated cell co-culture. Except for the TNF- $\alpha$ level that was slightly reduced (by 35\%), all angiogenic and inflammatory protein levels were suppressed moderately (by $35-75 \%$ ) to strongly $(>75 \%)$ after apocynin treatment (Table II).

\section{Discussion}

Although, a large body of data suggest that the infiltration of TAMs into tumors to a great extent are related with poor prognosis in most types of cancer (breast, bladder, urogenital, head and neck cancer) (32-34), the role of this microenvironmental cell type in colon carcinoma development is still controversial (16-19,34-38). Thus, the present study aimed to investigate the role of TAMs in colon carcinoma cell development. Therefore, the link between TAM-driven protumor processes and C26 murine colon carcinoma cell proliferation was evaluated in an in vitro co-culture model of murine macrophages and C26 tumor cells at a cell density ratio that approximates physiological conditions for colon carcinoma development in vivo (20). Our results demonstrated that TAMs enhanced proliferation of $\mathrm{C} 26$ colon carcinoma cells when they were co-cultivated (Fig. 1).

To gain insight into the molecular mechanisms of the proliferative actions of TAMs on C26 cells, TAM-mediated 
Table II. Involvement of TAM-induced NADPH-oxidase in the production of angiogenic proteins in the co-culture model.

Percentage of inhibition (-) of angiogenic proteins in the co-culture of $\mathrm{C} 26$ cells and macrophages compared to Angiogenic apocynin-treated co-culture of proteins C26 cells and macrophages

\begin{tabular}{ll}
\hline Granulocyte CSF & $-49.54 \pm 1.05^{\mathrm{a}}$ \\
Granulocyte-macrophage CSF & $-55.20 \pm 1.93^{\mathrm{a}}$ \\
Macrophage-CSF & $-74.51 \pm 1.87^{\mathrm{a}}$ \\
Insulin-like growth factor II & $-75.18 \pm 5.44^{\mathrm{a}}$ \\
IL-1 $\alpha$ & $-67.89 \pm 1.74^{\mathrm{a}}$ \\
IL-1 $\beta$ & $-71.64 \pm 2.02^{\mathrm{a}}$ \\
IL-6 & $-43.87 \pm 2.12^{\mathrm{a}}$ \\
IL-9 & $-79.25 \pm 0.50^{\mathrm{a}}$ \\
IL-12p40 & $-84.57 \pm 14.15^{\mathrm{a}}$ \\
IL-13 & $-48.17 \pm 1.92^{\mathrm{a}}$ \\
Tumor necrosis factor- $\alpha$ & $-32.23 \pm 4.19^{\mathrm{a}}$ \\
Monocyte chemoattractant protein-1 & $-77.30 \pm 0.40^{\mathrm{a}}$ \\
Eotaxin & $-45.41 \pm 15.04^{\mathrm{a}}$ \\
Fas ligand & $-56.75 \pm 2.55^{\mathrm{a}}$ \\
Basic fibroblast growth factor & $-60.08 \pm 1.74^{\mathrm{a}}$ \\
Vascular endothelial growth factor & $-65.72 \pm 0.81^{\mathrm{a}}$ \\
Leptin & $-85.54 \pm 4.01^{\mathrm{a}}$ \\
Thrombopoietin & $-69.97 \pm 0.41^{\mathrm{a}}$ \\
TIMP-1 & $-54.77 \pm 4.51^{\mathrm{a}}$ \\
TIMP-2 & $-53.56 \pm 0.14^{\mathrm{a}}$ \\
Platelet factor 4 & $-65.65 \pm 1.09^{\mathrm{a}}$ \\
IL-12p70 & $-28.79 \pm 6.82^{\mathrm{a}}$ \\
Interferon- $\gamma$ & $-74.38 \pm 0.56^{\mathrm{a}}$ \\
Monokine induced by interferon- $\gamma$ & $-55.09 \pm 4.12^{\mathrm{a}}$ \\
\hline
\end{tabular}

Statistical differences were evaluated using two-way ANOVA with Bonferroni post tests and indicated as ${ }^{a} \mathrm{P}<0.0001$. TAMs, tumor-associated macrophages; CSF, colony-stimulating factor; IL, interleukin; TIMP, tissue inhibitor of metalloproteinases.

protumor processes such as inflammation, angiogenesis and oxidative stress were investigated. Firstly, the expression of the inflammatory transcription factor, NF- $\kappa \mathrm{B}$ was assessed as the active form as well as total protein (as the active and inactive form). It is known that NF- $\kappa \mathrm{B}$ is a pleiotropic transcriptional regulator constitutively expressed and activated in most colon carcinoma cells including C26 cells (39). This protein controls the expression of numerous genes encoding for growth factors (VEGF and FGF), cytokines and chemokines (TNF- $\alpha$ and IL-8), and metalloproteinases, which are involved in tumor inflammation, angiogenesis, cell proliferation, tumor survival and chemoresistance $(40,41)$. Moreover, $\mathrm{NF}-\kappa \mathrm{B}$ ensures crosstalk between colon carcinoma and stromal cells in the tumor microenvironment which is essential for tumor progression $(42,43)$. Our results showed that the total production of NF- $\kappa \mathrm{B}$ was not influenced by the co-cultivation of $\mathrm{C} 26$ cells with TAMs albeit the activation of $\mathrm{NF}-\kappa \mathrm{B}$ was drastically affected (by $70 \%$ ) in the cell co-culture lysates compared to transcription factor activation in $\mathrm{C} 26$ cell lysates (Fig. 2A and B). Several studies are consistent with our data showing the inactivation of $\mathrm{NF}-\kappa \mathrm{B}$ in TAMs as a result of the primary necessity of cancer cells to maintain these immune cells in a suppressed state vital for tumor cell proliferation and invasion $(44,45)$. Moreover, the antitumor role of $\mathrm{NF}-\kappa \mathrm{B}$ activation in TAMs is also supported by previous findings regarding its antimetastatic activity in a mammary tumor lung metastasis model (46). In addition to these data, several studies proved the dual role of $\mathrm{NF}-\kappa \mathrm{B}$ in tumorigenesis in a manner dependent on cell type (47). Thus, NF- $\kappa \mathrm{B}$ activation in tumor cells is responsible for the expression of anti-apoptotic, proliferative, and pro-angiogenic molecules while its activation in endothelial cells is linked to inhibition of tumor angiogenesis (47). Although our studies involved macrophages instead of endothelial cells, we noted that the levels of the active form of NF- $\kappa \mathrm{B}$ correlated negatively with the proliferation of $\mathrm{C} 26$ cells (Pearson correlation coefficient $r=-0.991 ; \mathrm{P}<0.0001$ ) and also with the levels of pro-angiogenic molecules (Pearson correlation coefficient $\mathrm{r}=-0.793 ; \mathrm{P}=0.0007$ ) in cell lysates. Collectively, our data suggest that the proliferative effects of TAMs on C26 cells may be related to the anti-inflammatory role of these cells in the tumor microenvironment via reduction of NF- $\kappa \mathrm{B}$ activation (Fig. 2A and B) as well as the stimulatory activity of TAMs on the production of most of the angiogenic proteins tested in the cell co-culture (Table I).

Furthermore, since pro-angiogenic protein production and $\mathrm{NF}-\kappa \mathrm{B}$ activation are modulated by ROS levels in the tumor microenvironment (48-52), we evaluated oxidative stress in C26 cells as well as in the co-culture of C26 cells and TAMs. Thus we assessed the levels of the oxidative stress marker, MDA and total nonenzymatic antioxidant systems, and catalytic activity of catalase under both culture conditions. Our results suggested that TAMs are important contributors in producing the proliferative levels of ROS in the $\mathrm{C} 26$ carcinoma microenvironment $(4,52)$ since MDA levels doubled when C26 cells were co-cultivated with macrophages (Fig. 3A). Moreover, TAMs may help C26 cells to protect themselves from microenvironmental oxidative stress mainly via enhancement of the production of nonenzymatic antioxidant defense systems under co-culture conditions (Fig. 3A-C). Furthermore, our data proved that NADPH oxidase has the main role in supporting the $\mathrm{C} 26$ carcinoma cell oxidative stress as the levels of the oxidative stress marker (MDA) as well as antioxidant defense mechanisms in the tumor microenvironment (particularly via nonenzymatic antioxidant systems) were reduced significantly after quenching NADPH oxidase activity under co-culture conditions (Fig. 4A-C). The activity of NADPH oxidase from the plasma membrane of macrophages was also responsible for the stimulatory effects of TAMs on the proliferation of C26 cells (Fig. 4D) mainly via enhancement of the pro-angiogenic protein production in the co-culture microenvironment (Table II). Thus, abolishment of NADPH oxidase activity after apocynin administration reduced strongly the levels of all angiogenic proteins tested in the cell co-culture lysates. Nevertheless, the apocynin effect on the co-culture of C26 cells with TAMs did not affect the anti-inflammatory effects of these cells on the activation of $\mathrm{NF}-\kappa \mathrm{B}$ in the $\mathrm{C} 26$ carcinoma milieu (Fig. 5A and B) and did not totally counteract the pro-angiogenic actions of TAMs on 
C26 cells [average enhancing effect of TAMs on angiogenic protein production in cell co-culture $(\sim 112 \%)$ (Table I) was higher than reducing effect of the same protein production after apocynin administration (by 63\%) (Table II)]. These findings suggest that TAMs also support C26 carcinoma cell proliferation via additional effects to the main mechanism based on NADPH oxidase-generated tumor oxidative stress, probably via ROS-signaling-independent regulatory effects on different transcription factors involved in tumor-associated inflammation and angiogenesis (21).

In conclusion, our data support the stimulatory role of TAMs on C26 murine colon carcinoma cell proliferation via anti-inflammatory, pro-angiogenic and pro-oxidant effects on the co-culture microenvironment. The main mechanism of the protumor function of TAMs in C26 tumor development is based on the maintenance of the physiological range of the oxidative stress and angiogenic capacity of the C26 colon carcinoma milieu via NADPH oxidase activity. Moreover, in addition to this principal mechanism of action, the anti-inflammatory and pro-angiogenic effects of TAMs on these cancer cells create a favorable microenvironment for C26 colon carcinoma development and progression. These findings provide new insights into tumor-targeted therapies based on 're-education' strategies of TAMs.

\section{Acknowledgements}

The present study was supported by the UEFISCDI (Romanian Ministry of Education, Research and Innovation) (project PN-II-PT-PCCA-2011-3-2-1060, contract no. 95/2012 and project PN-II-RU-TE-2014-4-1191, contract no. 235/01.10.2015), and the Sectorial Operational Programme for Human Resources Development 2007-2013, co-financed by the European Social Fund (project POSDRU/187/1.5/S/155383-'Quality, Excellence, Transnational Mobility in Doctoral Research').

\section{References}

1. Albini A, Tosetti F, Benelli R and Noonan DM: Tumor inflammatory angiogenesis and its chemoprevention. Cancer Res 65: 10637-10641, 2005.

2. Allavena P, Sica A, Garlanda C and Mantovani A: The Yin-Yang of tumor-associated macrophages in neoplastic progression and immune surveillance. Immunol Rev 222: 155-161, 2008.

3. Quail DF and Joyce JA: Microenvironmental regulation of tumor progression and metastasis. Nat Med 19: 1423-1437, 2013.

4. Alupei MC, Licarete E, Patras L and Banciu M: Liposomal simvastatin inhibits tumor growth via targeting tumor-associated macrophages-mediated oxidative stress. Cancer Lett 356: 946-952, 2015.

5. Banciu M, Metselaar JM, Schiffelers RM and Storm G: Antitumor activity of liposomal prednisolone phosphate depends on the presence of functional tumor-associated macrophages in tumor tissue. Neoplasia 10: 108-117, 2008.

6. Mantovani A, Sica A, Sozzani S, Allavena P, Vecchi A and Locati M: The chemokine system in diverse forms of macrophage activation and polarization. Trends Immunol 25: 677-686, 2004.

7. Solinas G, Germano G, Mantovani A and Allavena P: Tumorassociated macrophages (TAM) as major players of the cancer-related inflammation. J Leukoc Biol 86: 1065-1073, 2009.

8. Mantovani A, Sozzani S, Locati M, Allavena P and Sica A: Macrophage polarization: Tumor-associated macrophages as a paradigm for polarized M2 mononuclear phagocytes. Trends Immunol 23: 549-555, 2002.

9. Brown NS and Bicknell R: Hypoxia and oxidative stress in breast cancer. Oxidative stress: Its effects on the growth, metastatic potential and response to therapy of breast cancer. Breast Cancer Res 3: 323-327, 2001.
10. Brown NS, Jones A, Fujiyama C, Harris AL and Bicknell R: Thymidine phosphorylase induces carcinoma cell oxidative stress and promotes secretion of angiogenic factors. Cancer Res 60: 6298-6302, 2000.

11. Fruehauf JP and Meyskens FL Jr: Reactive oxygen species: A breath of life or death? Clin Cancer Res 13: 789-794, 2007.

12. Guo C, Buranych A, Sarkar D, Fisher PB and Wang XY: The role of tumor-associated macrophages in tumor vascularization. Vasc Cell 5: 20, 2013.

13. Sundaresan M, Yu ZX, Ferrans VJ, Sulciner DJ, Gutkind JS, Irani K, Goldschmidt-Clermont PJ and Finkel T: Regulation of reactive-oxygen-species generation in fibroblasts by Rac1. Biochem J 318: 379-382, 1996.

14. Tammali R, Reddy AB, Srivastava SK and Ramana KV: Inhibition of aldose reductase prevents angiogenesis in vitro and in vivo. Angiogenesis 14: 209-221, 2011.

15. Zhang Y, Choksi S, Chen K, Pobezinskaya Y, Linnoila I and Liu ZG: ROS play a critical role in the differentiation of alternatively activated macrophages and the occurrence of tumor-associated macrophages. Cell Res 23: 898-914, 2013.

16. Forssell J, Oberg A, Henriksson ML, Stenling R, Jung A and Palmqvist R: High macrophage infiltration along the tumor front correlates with improved survival in colon cancer. Clin Cancer Res 13: 1472-1479, 2007.

17. Sickert D, Aust DE, Langer S, Haupt I, Baretton GB and Dieter P: Characterization of macrophage subpopulations in colon cancer using tissue microarrays. Histopathology 46: 515-521, 2005.

18. van der Bij GJ, Bögels M, Oosterling SJ, Kroon J, Schuckmann DT, de Vries HE, Meijer S, Beelen RH and van Egmond M: Tumor infiltrating macrophages reduce development of peritoneal colorectal carcinoma metastases. Cancer Lett 262: 77-86, 2008.

19. Zins K, Abraham D, Sioud M and Aharinejad S: Colon cancer cell-derived tumor necrosis factor-alpha mediates the tumor growth-promoting response in macrophages by up-regulating the colony-stimulating factor-1 pathway. Cancer Res 67: 1038-1045, 2007.

20. Calorini L, Bianchini F, Mannini A, Mugnai G and Ruggieri S: Enhancement of nitric oxide release in mouse inflammatory macrophages co-cultivated with tumor cells of a different origin. Clin Exp Metastasis 22: 413-419, 2005.

21. Herbeuval JP, Lelievre E, Lambert C, Dy M and Genin C: Recruitment of STAT3 for production of IL-10 by colon carcinoma cells induced by macrophage-derived IL-6. J Immunol 172: 4630-4636, 2004.

22. James AD, Patel W, Butt Z, Adiamah M, Dakhel R, Latif A, Uggenti C, Swanton E, Imamura H, Siriwardena AK, et al: The plasma membrane calcium pump in pancreatic cancer cells exhibiting the Warburg effect relies on glycolytic ATP. J Biol Chem 290: 24760-24771, 2015.

23. Banciu M, Schiffelers RM, Fens MH, Metselaar JM and Storm G: Anti-angiogenic effects of liposomal prednisolone phosphate on B16 melanoma in mice. J Control Release 113: 1-8, 2006.

24. Siu FKY, Lee LTO and Chow BKC: Southwestern blotting in investigating transcriptional regulation. Nat Protoc 3: 51-58, 2008.

25. Bradford MM: A rapid and sensitive method for the quantitation of microgram quantities of protein utilizing the principle of protein-dye binding. Anal Biochem 72: 248-254, 1976.

26. Karin M and Greten FR: NF-kappaB: Linking inflammation and immunity to cancer development and progression. Nat Rev Immunol 5: 749-759, 2005.

27. Karatas F, Karatepe M and Baysar A: Determination of free malondialdehyde in human serum by high-performance liquid chromatography. Anal Biochem 311: 76-79, 2002.

28. Erel O: A novel automated direct measurement method for total antioxidant capacity using a new generation, more stable ABTS radical cation. Clin Biochem 37: 277-285, 2004.

29. Aebi H: Catalase in vitro. Methods Enzymol 105: 121-126, 1984.

30. Sica A and Bronte V: Altered macrophage differentiation and immune dysfunction in tumor development. J Clin Invest 117: 1155-1166, 2007.

31. Pick E: Role of the Rho GTPase Rac in the activation of the phagocyte NADPH oxidase: Outsourcing a key task. Small GTPases 5: e27952, 2014.

32. Zhang QW, Liu L, Gong CY, Shi HS, Zeng YH, Wang XZ, Zhao YW and Wei YQ: Prognostic significance of tumorassociated macrophages in solid tumor: A meta-analysis of the literature. PLoS One 7: e50946, 2012.

33. Biswas SK, Allavena P and Mantovani A: Tumor-associated macrophages: Functional diversity, clinical significance, and open questions. Semin Immunopathol 35: 585-600, 2013. 
34. Siveen KS and Kuttan G: Role of macrophages in tumour progression. Immunol Lett 123: 97-102, 2009.

35. van der Bij GJ, Oosterling SJ, Meijer S, Beelen RH and van Egmond M: The role of macrophages in tumor development. Cell Oncol 27: 203-213, 2005.

36. Coffelt SB, Hughes R and Lewis CE: Tumor-associated macrophages: Effectors of angiogenesis and tumor progression. Biochim Biophys Acta 1796: 11-18, 2009.

37. Joyce JA and Pollard JW: Microenvironmental regulation of metastasis. Nat Rev Cancer 9: 239-252, 2009.

38. Barbera-Guillem E, Nyhus JK, Wolford CC, Friece CR and Sampsel JW: Vascular endothelial growth factor secretion by tumor-infiltrating macrophages essentially supports tumor angiogenesis, and IgG immune complexes potentiate the process. Cancer Res 62: 7042-7049, 2002.

39. Patras L, Sesarman A, Licarete E, Luca L, Alupei MC, Rakosy-Tican E and Banciu M: Dual role of macrophages in the response of $\mathrm{C} 26$ colon carcinoma cells to 5-fluorouracil administration. Oncol Lett 12: 1183-1191, 2016.

40. Yang Z, Li C, Wang X, Zhai C, Yi Z, Wang L, Liu B, Du B, Wu H, Guo X, et al: Dauricine induces apoptosis, inhibits proliferation and invasion through inhibiting NF-kappaB signaling pathway in colon cancer cells. J Cell Physiol 225: 266-275, 2010.

41. Ryan AE, Colleran A, O'Gorman A, O'Flynn L, Pindjacova J, Lohan P, O'Malley G, Nosov M, Mureau C and Egan LJ: Targeting colon cancer cell NF- $\kappa \mathrm{B}$ promotes an anti-tumour M1-like macrophage phenotype and inhibits peritoneal metastasis. Oncogene 34: 1563-1574, 2015.

42. Grivennikov SI and Karin M: Dangerous liaisons: STAT3 and NF-kappaB collaboration and crosstalk in cancer. Cytokine Growth Factor Rev 21: 11-19, 2010.

43. Lin WW and Karin M: A cytokine-mediated link between innate immunity, inflammation, and cancer. J Clin Invest 117: $1175-1183,2007$.
44. Saccani A, Schioppa T, Porta C, Biswas SK, Nebuloni M, Vago L, Bottazzi B, Colombo MP, Mantovani A and Sica A: p50 nuclear factor-kappaB overexpression in tumor-associated macrophages inhibits M1 inflammatory responses and antitumor resistance. Cancer Res 66: 11432-11440, 2006.

45. Kühnemuth B and Michl P: The role of CUX1 in antagonizing NF- $\kappa$ B signaling in TAMs. OncoImmunology 3: e28270, 2014.

46. Connelly L, Barham W, Onishko HM, Chen L, Sherrill TP, Zabuawala T, Ostrowski MC, Blackwell TS and Yull FE: NF-kappaB activation within macrophages leads to an anti-tumor phenotype in a mammary tumor lung metastasis model. Breast Cancer Res 13: R83, 2011.

47. Tabruyn SP and Griffioen AW: A new role for NF-kappaB in angiogenesis inhibition. Cell Death Differ 14: 1393-1397, 2007.

48. Ushio-Fukai M and Alexander RW: Reactive oxygen species as mediators of angiogenesis signaling: Role of NAD(P)H oxidase. Mol Cell Biochem 264: 85-97, 2004.

49. Morgan MJ and Liu ZG: Crosstalk of reactive oxygen species and NF- $\kappa \mathrm{B}$ signaling. Cell Res 21: 103-115, 2011.

50. Kabe Y, Ando K, Hirao S, Yoshida M and Handa H: Redox regulation of NF-kappaB activation: Distinct redox regulation between the cytoplasm and the nucleus. Antioxid Redox Signal 7: 395-403, 2005

51. Wu M, Bian Q, Liu Y, Fernandes AF, Taylor A, Pereira P and Shang F: Sustained oxidative stress inhibits NF-kappaB activation partially via inactivating the proteasome. Free Radic Biol Med 46: 62-69, 2009.

52. Alupei MC, Licarete E, Cristian FB and Banciu M: Cytotoxicity of lipophilic statins depends on their combined actions on HIF-1 $\alpha$ expression and redox status in B16.F10 melanoma cells. Anticancer Drugs 25: 393-405, 2014. 